86 Tropelías. Revista de Teoría de la Literatura y Literatura Comparada, número extraordinario 6 (2020) Alfredo Saldaña Sagredo

\title{
SOBRE LITERATURA Y PENSAMIENTO CRÍTICO EN LA POSMODERNIDAD
}

\section{ON LITERATURE AND CRITICAL THINKING IN POSTMODERNITY}

\section{Alfredo SALDAÑN SAGREDO}

Universidad de Zaragoza

\begin{abstract}
Resumen: En estas páginas trataré de localizar algunas derivas culturales en el contexto epistémico de la posmodernidad en las que la teoría es todavía una herramienta de cuestionamiento crítico. En estas condiciones, la literatura ya no puede explicarse a partir de los planteamientos estéticos más tradicionales y ortodoxos, sino que se hace necesario abordar sus diferentes prácticas a la luz de una filosofía crítica de la cultura que nos oriente en ese complejo panorama.
\end{abstract}

Palabras claves: Literatura. Teoría de la literatura. Pensamiento crítico. Posmodernidad

Abstract: In these pages I aim to locate certain cultural drifts in which theory still proves to be a critical questioning tool within the epistemic context of postmodernity. Under these conditions, literature can no longer be explained with the more traditional and orthodox aesthetic approaches; it rather becomes necessary to address its different practices in the light of a critical philosophy of culture that may guide us in such complex panorama.

Keywords: Literature. Literary Theory. Critical thinking. Postmodernity. 


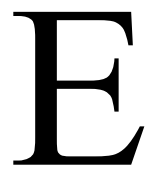
n algún momento de la historia del pensamiento occidental, la filosofía y la poesía se distanciaron entre sí y comenzaron a transitar por sus particulares senderos. Ese instante aciago marcó el inicio de una andadura en la que el pensamiento y la imaginación dejaron de cooperar como dos herramientas adecuadas en el desvelamiento de los conflictos y los interrogantes vinculados con el ser, la realidad, el mundo, el tiempo, etc. Trataré en estas páginas de localizar algunas derivas culturales en el contexto epistémico de la posmodernidad en las que la teoría es todavía una herramienta de cuestionamiento crítico y donde emergen acciones capaces de subvertir modelos dominantes de vida. De paso, intentaré entender dicho contexto como un proceso que genera las coordenadas antropológicas de tiempo y espacio de la actualidad para que surjan las interpretaciones, como un instante y un escenario abiertos entre las grietas que separan el acontecimiento del sentido, la incesante producción de acontecimientos de la inagotable generación de sentidos. Y atravesándolo todo, la literatura, un lenguaje sin lugar y casi sin identidad, golpeado por todos los vientos.

Desde hace ya unas cuantas décadas, estamos asistiendo a la explosión de las condiciones de tiempo y espacio con las que estructuramos la realidad y en ella la experiencia de nuestras vidas. La posmodernidad (una época que ha recogido el legado de las teorías de la relatividad elaboradas por Albert Einstein a comienzos del siglo XX, todavía en plena modernidad) conoce la presencia de un entorno virtual y un momento discontinuo, elástico y multidireccional, intuye —a partir de algunas categorías heredadas de la modernidad: indeterminación, incertidumbre (Werner Heisenberg), desequilibrio, inestabilidad - que hay fenómenos y procesos no lineales e impredecibles y desarrolla inéditas modalidades de escritura con nuevas implicaciones sociales y culturales. Frente a una modernidad que supo medir los tiempos del trabajo y el ocio y localizar los espacios de la existencia y la emancipación, nos encontramos ahora en una posmodernidad discontinua y heterotópica, descentrada, obligada a transitar a la búsqueda de esos centros nómadas deleuzianos que representan la provisionalidad, la inestabilidad y la fragilidad de todo saber. En este contexto, a la luz de los cambios históricos y tecnológicos de nuestro tiempo, sobre este nuevo escenario transnacional, en estas páginas propongo una reflexión sobre el lugar que ocupan y las funciones que desempeñan la teoría y la práctica de la literatura, todo ello en una época posterior a lo que podríamos denominar «alta teoría» (Eagleton, 2005: 14).

En estas condiciones, se hace necesario abordar las diferentes prácticas literarias a la luz de una conciencia ecológica que entienda el lenguaje ya no solo como un problema de crítica filológica o de talento literario sino como el lugar en el que pueden surgir la creatividad, la crítica y el contacto más intenso con nosotros mismos y con los demás (Bordelois, 2005), una filosofía crítica de la cultura que sea capaz de orientarnos en ese complejo y a veces caótico panorama que dibuja la cultura poshistórica, en la que, como podemos comprobar a menudo, todo puede ser posible, incluso el arte antiestético. Algunos críticos consideran que este arte prolonga la «alteración» — détournement- 
situacionista, y no es descabellado pensar eso dado de Guy Debord y sus compañeros de viaje —al entender la ciudad como un espacio atravesado por continuas derivas y líneas de fuga - no dejaron de proyectar escenarios abiertos en los que poder ubicar un pensamiento esencialmente nómada e inestable. En fin, una reflexión como la que quiero plantear en estas páginas solo tiene sentido si se aborda como un esfuerzo para ubicar los lugares que ocupan el arte y la literatura en las sociedades contemporáneas y las relaciones e interacciones que se producen «entre la teoría del lenguaje, la teoría del arte y de la literatura, la ética y lo político» (Meschonnic, 2017: 12).

Dado que, como recuerda el propio Meschonnic (2017), lo posmoderno remite a una época y no tanto a un determinado movimiento estético o cultural, la construcción de la idea de la posmodernidad - esa sería, en esencia, la cuestión disputada - se aborda de múltiples maneras, desde puntos de vista especializados o de forma interdisciplinar, transversal, desde la antropología o la teoría de los medios de comunicación de masas, la semiótica o la crítica literaria, hasta la estética o la crítica política y cultural, con los más variados y a veces enfrentados argumentos filosóficos y epistemológicos, desde la teoría social o las posiciones más innovadoras de la lingüística y la ingeniería telemática hasta los estudios culturales o la teoría literaria que trabaja ya sobre un escenario posnacional. En estas circunstancias, nos encontramos con una posmodernidad ambivalente y contradictoria que, por un lado, a través de un lenguaje cada vez más depauperado fomenta la aparición de escenarios abiertos, dialógicos, descentrados y desjerarquizados (podría decirse que, aparentemente, más democráticos), pero, por otro, ha permitido que eso que denominamos «opinión pública» responda a intereses privados, convirtiéndose al final en una ilusión, una falacia: «la cultura masificante desconfía del lenguaje porque, como lo hemos dicho, la conciencia crítica de la lengua es el comienzo de toda crítica» (Bordelois, 2005: 31). Una posmodernidad que ha conocido un desarrollo tecnológico sin precedentes en cuanto a sistemas de comunicación, grabación y almacenamiento de datos se refiere y, al mismo tiempo, ha mostrado un particular interés por lo que de efímero y procesual tienen algunas manifestaciones artísticas (land art, happening, performance); una posmodernidad que ha presenciado el deterioro de las ideologías tradicionales y de los grandes discursos de emancipación fundados en esas mismas ideologías, un desgaste que ha propiciado el surgimiento de diferentes modos de conocimiento, explicación y valoración de la realidad perfectamente diferenciados entre sí (Saldaña, 1997).

En este contexto, al margen de las clasificaciones binarias — verdad / mentira, belleza / fealdad, realidad / ficción, nación / mundo, etc.- que han condicionado durante siglos la historia del pensamiento occidental, ¿cómo construir un espacio no geográfico en el que pensar la literatura como un campo de fuerzas y de tensiones?, ¿qué respuestas puede ofrecer la literatura frente a los conflictos que surgen en el mundo contemporáneo?, ¿qué lugar deberían ocupar los estudios literarios en particular y las ciencias humanas en general en un mundo cada vez más marcado por el axioma mercantil de una utilidad productiva orientada hacia el beneficio económico?, ¿se puede ofrecer hoy una definición de literatura que recoja de una manera más o menos precisa sus diversas manifestaciones?, ¿en qué sentidos utilizamos ese término, literatura, y para referirnos a qué diferentes 
tipos de discursos?, ¿hasta qué punto es posible hablar de un lenguaje literario que se caracteriza por la ausencia de recursos retóricos o registros lingüísticos específicos?, una carencia que, sin embargo, no impidió a teóricos como Wellek y Warren defender la existencia de un uso singularmente literario del lenguaje en el que la función estética es la dominante, una práctica que se inicia en una experiencia privada y se materializa públicamente en una dimensión social, un horizonte de sentidos compartidos por el autor y los lectores.

A lo largo de su historia, la literatura se ha entendido como una actividad con diferentes implicaciones políticas, económicas, éticas, estéticas, simbólicas y espirituales en el ámbito de la sociedad en la que aparece. Durante buena parte de la historia cultural de la humanidad, y en determinados momentos de una forma particularmente intensa, las obras literarias se han entendido como creaciones merecedoras de aprecio y no como construcciones llamadas a ser analizadas y comprendidas. Es sabido que las disciplinas encargadas de ordenar la literatura como institución social (retórica, preceptiva, poética, historia, teoría y crítica literarias, filosofía de la literatura, literatura comparada, etc.) se han ocupado de sistematizar y regular su estudio, es decir, se han dedicado a introducir jerarquías y prioridades, valores y sentidos. Si nos fijamos en las muy diversas funciones que la literatura ha desempeñado a lo largo del tiempo, es un hecho que se trata de una práctica en la que encontramos numerosos perfiles, nada, por lo tanto, esencial, dotada además de una gran diversidad temática y formal. Hablamos de una experiencia histórica cuyo estudio fue dotándose de un estatuto científico a partir del romanticismo, en un primer momento con paradigmas de tradición filológica y humanista (crítica textual), alimentados en ocasiones por un positivismo demasiado estrecho (historia literaria), dotados luego de un aparato conceptual y epistemológico cada vez más complejo (crítica literaria, teoría literaria, literatura comparada), hasta alcanzar en las últimas décadas disciplinas un tanto híbridas en su formación que se nutren de modelos teóricos, filosóficos y culturales tan dispares como el marxismo, el psicoanálisis, la fenomenología, la hermenéutica, el estructuralismo, la deconstrucción o la etnología y la sociología críticas.

La irrupción de todas esas disciplinas científicas ha mostrado en estas últimas décadas el agotamiento de un paradigma no tanto histórico como historicista (nada o muy poco atento a la existencia de fenómenos como la intertextualidad, la poligénesis, el entretejimiento de diferentes lenguajes artísticos o las relaciones entre distintos ámbitos culturales) y el extraordinario desarrollo que han experimentado los estudios de teoría literaria, historia comparada de la literatura y teoría de la historia literaria, que han apostado por un nuevo concepto de «historia literaria» marcadamente crítico, ideológico y estético, más atento a las relaciones que se dan entre diferentes literaturas que al desarrollo de una literatura en particular: «literary history is always a potential field of tensions within a given ideological situation» (Ljung, 2006: 40), un concepto disciplinario que afronta el estudio de la literatura sobre un escenario transcultural y supranacional —o posnacional, si optamos por utilizar un término formado con un prefijo muy característico de la actual globalización posmoderna-, y todo ello en un mundo en el que las coordenadas antropológicas de tiempo y espacio han sido dinamitadas debido a la irrupción del ciberespacio, ese espacio-tiempo virtual de alcance global y aparición 
instantánea, un mundo en el que la nación no es ni puede seguir siendo el referente sobre el que construir la historia literaria o, sin más, la historia (Perkins, 1991; Hutcheon y Valdés, 2002; AA. VV., 2006). En estas circunstancias, carece de rigor crítico continuar empeñándose en redactar historias de las diferentes literaturas nacionales con los mismos planteamientos, intereses y objetivos con que se escribieron desde las primeras décadas del siglo XIX hasta, por lo menos, mediados del siglo pasado. El mundo es hoy otra cosa y el papel desempeñado en él por las naciones muy diferente al que pudieron ejercer en el pasado. Y al margen de estos factores que ponen en cuestión no solo las relaciones de la literatura con la identidad nacional sino también el propio estatuto literario, es un hecho que en la actualidad la función de la literatura es carecer de función (por lo menos en los sentidos de utilidad, rentabilidad y razón económica que usualmente atribuimos a este sustantivo, probablemente por resultar esos sentidos —en realidad, similares versiones de un mismo sentido- los únicos dominantes). Sin embargo, esa funcionalidad ha sido en ocasiones un elemento determinante y se ha entendido de muy diversas maneras a lo largo de la historia, de tal modo que la práctica literaria se ha asociado al fomento de creencias religiosas y valores morales, sistemas políticos y culturales, métodos terapéuticos y balsámicos. La literatura funciona entonces como una válvula de escape, un antídoto con el que la gente afronta unas vidas marcadas por la carencia, la adversidad y la violencia generadas por un sistema social y económico radicalmente injusto (Saldaña, 2004).

En este sentido, es evidente que la literatura no puede desvincularse de una circulación social distorsionada en gran medida por el consumo y la recepción; es indudable también que dicha actividad, en su proyección pública, se encuentra más vinculada con el valor de cambio que con el valor de uso, más próxima al mercado literario que a la estética literaria y que, en un mundo como este, lastrado por un capitalismo económico, cultural y cognitivo arrollador, cuanto más amplia sea esa recepción más valor y autoridad alcanzarán los objetos consumidos en el campo literario. En fin, todo esto forma parte de esos prejuicios que han hecho costra en la piel de nuestro imaginario colectivo orientando actitudes, gustos y sensibilidades. Así pues, sería muy conveniente levantar esa capa para entrever que lo que se oculta bajo su superficie es reflejo de la diversidad y complejidad del mundo y no solo de los intereses del mercado. A estas alturas no deja de ser un lugar común el señalar que la literatura adquiere sentido como práctica significativa en su circulación social, un movimiento controlado en gran medida por agentes económicos (medios de comunicación de masas, grandes corporaciones, multinacionales y empresas financieras y comerciales con intereses en el sector editorial, etc.) que regulan y fiscalizan la comunicación literaria manipulando los gustos e intereses de los lectores. Ahora bien, durante buena parte de la historia cultural de la humanidad, y en determinados momentos de una manera particularmente intensa, las obras literarias se han entendido como creaciones merecedoras de aprecio y no como construcciones valoradas en función de la mejor o peor respuesta comercial que hayan tenido, cuestión que debería tenerse muy en cuenta en aquellas instituciones educativas (estoy pensando sobre todo en la Universidad) en donde la literatura es materia integrante de sus planes de estudios. 
En este contexto, el empobrecimiento de las propuestas literarias es notorio y se da la paradoja de que en un tiempo en el que se ha hecho bandera de la libertad se producen sofisticadísimas estrategias de (auto)censura que lastran el trabajo de unos escritores que, en general, renuncian a los rasgos que históricamente han caracterizado sus propuestas: exploración de la realidad, lucidez, sentido crítico, experimentalismo, riesgo, innovación, etc., unos escritores que, llegado el caso, hipnotizados por las prebendas que otorga el mercado (entre las que se encuentran el beneficio económico, el reconocimiento social y las sinecuras derivadas), no dudarán en traicionar - si es que alguna vez las tuvieron - sus ideas literarias y se decantarán por las formas, géneros y registros de mayor aceptación comercial; de este modo, nos encontramos con propuestas que se presentan como imposturas, creaciones que buscan el éxito inmediato y fácil, fórmulas que responden a estrategias con las que se intenta que esos textos sean bien recibidos en el seno del mercado: novelas de suspense con dosis aceptables de crítica social; relatos sentimentales que recuperan la historia con benevolencia; propuestas metalingüísticas con ingredientes fantásticos y de ciencia-ficción (Sanz, 2014). En todas estas modalidades, y en todos los niveles, el grado de exigencia artística ha disminuido de manera preocupante hasta el punto de hablar, con una marcada connotación peyorativa, de paraliteratura, subliteratura, pseudoliteratura o literatura kleenex. En este sentido, la literatura, y especialmente la narrativa, «no sería muy distinta del pan y circo, del pan y toros, del pan y fútbol o del pan y telenovelas que caracterizó a multitud de regímenes totalitarios y que, hoy, caracteriza a democracias liberales que fomentan el concepto de una cultura de prestigio donde la cantidad —el número de ventas — es el criterio para establecer la calidad de una obra» (Sanz, 2014: 133).

En todo caso, y teniendo en cuenta que, por supuesto, el éxito comercial y la calidad literaria pueden coincidir en un mismo texto, se trata de cuestiones que demandan algún tipo de reajuste conceptual y que han ido perdiendo parte de su eficacia en estos últimos años, conforme se ha intensificado el perfil más economicista de la globalización y con él una cierta posmodernidad enemistada con las ideas de crítica y conflicto y proclive a entender y describir el mundo de una manera superficial y autocomplaciente. Y si a la proliferación de escuelas de escritores, talleres de escritura creativa y manuales de autoayuda que prometen la creatividad artística como una actividad al alcance de cualquiera, le sumamos un desinterés por la exigencia, el esfuerzo y el rigor que en otros momentos han sido rasgos constitutivos del trabajo artístico, nos encontramos con un panorama literario formalmente plano, estéticamente depauperado e ideológicamente reaccionario. En ese espectáculo participan editores que, obsesionados por la rentabilidad económica, han olvidado la dimensión cultural de su actividad profesional y escritores que desarrollan su trabajo a la sombra de la ansiedad no de la influencia sino de la celebridad o la confluencia (Aparicio Maydeu, 2015); muchos de esos escritores, conocedores de las leyes económicas que regulan el mercado editorial, renuncian a la soledad y el silencio cómplices de cualquier trabajo creativo y se integran en alianzas, espacios, grupos y redes comunes con la única intención de medrar y promocionarse más fácilmente. $\mathrm{Y}$ editores y escritores como esos encuentran su correlato adecuado y necesario no en una comunidad de lectores con espíritu crítico sino en una asociación de consumidores de lecturas que entienden dicha ocupación 
92 Tropelías. Revista de Teoría de la Literatura y Literatura Comparada, número extraordinario 6 (2020) Alfredo Saldaña Sagredo

como un ingrediente más de su ocio. El editor que ha conquistado una cuota de mercado luchará con todas sus fuerzas materiales por mantener e incluso aumentar su presencia económica en el mismo. El escritor trabaja para el mercado; con su escritura lo mantiene y el mercado le corresponde con sus reconocimientos económicos. Es un toma y daca en el que la literatura adopta la forma de una mercancía destinada a ser consumida por un cliente. Y en todo ese entramado participa un lector particular, el crítico literario, un espécimen cuyo perfil aparece ya dibujado en la Poética aristotélica que entiende en ocasiones su trabajo no de una manera independiente sino como un publicista, un vocero vendido al servicio de determinados privilegios sociales e intereses comerciales. En estas circunstancias, parece más una excepción a la regla que una norma habitual de conducta el hecho de que el escritor asuma compromisos con el lenguaje, la escritura, la estética, etc.; en esas mismas coyunturas, que el lector entienda el consumo como una oportunidad para ejercer su libertad de elección en un abanico amplísimo de posibilidades es, en realidad, casi siempre, una falacia dada la creciente concentración de empresas editoras, medios de comunicación y puntos de venta en unos pocos oligopolios. Claro que hay excepciones y quien escarbe un poco por debajo de la superficie encontrará sellos editoriales que no buscan solo la plusvalía económica, medios de comunicación interesados en contar la realidad de otras maneras y librerías en donde los textos literarios son algo más que unos meros productos de intercambio comercial (Saldaña, 2017).

Nos encontramos, de este modo, con una práctica literaria bastante extendida que enmascara una realidad que se percibe como algo fundamentalmente desagradable y molesto y, para ello, se apuesta por textos literarios que no buscan sino la complacencia y la complicidad de los lectores, operación que se produce a partir de un elemento constitutivo fundamental en todo este proceso: el mercado. En tanto que el neoliberalismo económico supone la capitalización y rentabilización de la realidad, esto es, en palabras de Perry Anderson (2000: 78), «la saturación de cada poro del mundo por el suero del capital», la literatura no puede explicarse al margen de ese capital, que todo lo invade y devora. La literatura no existe sin el mercado, ante cuyo altar se postra con la intención de adorarlo. Si la lógica capitalista reconoce la literatura en tanto que mercancía, el autor no puede sino asumir su papel de productor (la figura del trabajador sustituye a la imagen romántica del genio creador) de dicha mercancía. Marx ya entrevió esto al señalar con cierta sorna que un escritor es un obrero productivo, pero «no porque produzca ideas, sino porque enriquece a su editor» (Marx, 1945: 176).

Y ahí estamos desde hace ya algún tiempo, en un territorio donde el lector, el público, el receptor, el intérprete, el crítico, etc., categorías centrales en algunas corrientes del pensamiento literario contemporáneo, han sido barridas por el mercado, esa especie de metacategoría propedéutica desde la que, al parecer, todo se puede explicar. A lo largo de estos dos últimos siglos, el desarrollo de los diferentes itinerarios por los que han transcurrido la historiografía, la teoría y la crítica literarias ha suscitado la aparición de un nuevo escenario epistemológico y, para lo que aquí interesa, un replanteamiento de los objetivos, límites y estrategias de la filología; el campo literario, por decirlo de algún modo, como cualquier otro escenario de producción cultural, no deja de redefinir constantemente sus fronteras y eso hace que surjan fenómenos como las «literaturas sin residencia fija» (Ette, 2009: 
89), crecidas al margen de tradiciones y contextos nacionales y entendidas como manifestaciones apátridas de escrituras translingüísticas y transculturales (casos anómalos, por infrecuentes, a los que el pensamiento literario debería dar algún tipo de respuesta), o que literaturas hasta no hace mucho tiempo postergadas emerjan y se conviertan en el centro de atención de numerosos estudiosos, o que autores que hasta ayer mismo ocupaban una posición central en nuestro particular ranking literario hoy hayan sido desplazados hacia la periferia; en cualquier caso, ese campo no se presenta ni mucho menos como un territorio idílico sino que es el lugar en el que se dan constantes luchas internas en las que se dirimen, además de los temas e intereses que han de tratarse, la imagen y las fronteras del propio campo, un territorio condicionado por factores comerciales y económicos y que tiende a (con)fundirse muchas veces con el mercado literario, (con)fusión a la que aludía hace ya algunos años Sanz Villanueva (1996: 3): «Hoy no se puede decir nada acerca de nuestra novela si no hablamos del comercio».

En este sentido, como recuerda Terry Eagleton (2013), los ideólogos literarios en la Inglaterra victoriana se mostraron partidarios de extender entre la población el gusto por la lectura de unas obras literarias que podía provocar la evasión e incluso el olvido no solo de las lamentables condiciones en que vivían sino también de las causas que habían generado esas situaciones; en estos casos, la lectura literaria se presenta como una alternativa a la revolución; frente a ese tipo de literatura autocomplaciente y evasiva, es un hecho que existe otro tipo de literatura política - aunque quizás habría que preguntarse cuál en cierto modo no lo es - en la que «revolución de lenguaje y lenguaje de la revolución no sean marbetes antagónicos» (Sanz, 2014: 82), una literatura que no deje de cuestionar los límites entre los géneros, que traspase los registros expresivos y los cauces estilísticos más en boga y en la que la lectura sea una experiencia marcada por el desafío y la incertidumbre, la ventana abierta a un paisaje que se encuentra todavía por descubrir. Desde este punto de vista, esa experiencia no puede darse con una literatura orientada hacia el consumo y en la que la ideología consumista condiciona su propia práctica puesto que en dicho escenario la lectura suele responder a estereotipos y fórmulas prefijadas de antemano por unos «bancos de opinión» y unos medios de comunicación de masas que suelen compartir objetivos económicos y, en ese sentido, sus estrategias pasan por publicitar textos que alaban los fundamentos del sistema social imperante, textos que se encuentran más cerca de los sermones, los catecismos, las loas, los manifiestos o los panfletos que de la literatura. Con esos planteamientos, generan una literatura bastante autocomplaciente y poco dada a mostrar los conflictos sociales del presente.

Esa «nueva historia literaria» a la que me he referido más arriba —que ha desarrollado esfuerzos por revisar el canon y ha tratado de recuperar textos desplazados a la periferia por grupos partidarios de una ortodoxia literaria basada en el centro y la pureza - debe mantenerse alerta frente a los constantes cambios que se producen en el escenario artístico contemporáneo, cambios que — por lo que respecta a la literatura - afectan a la delimitación y definición de géneros, tradiciones, escuelas, movimientos, jerarquías, fronteras, límites, centros y fuentes de influencia (elementos todos ellos que deberían volverse a pensar) $\mathrm{y}$, de este modo, «we must think in terms of a quite different model of 
literary history» dado que esa historia literaria «in any of the forms in which it is now usually practiced has lost much of its force» (Frow, 1991: 137 y 142); se trata, pues, de una nueva disciplina que trabaja al margen de las categorías de nación y lengua nacional, desde una perspectiva global, transcultural, y por estudios literarios transculturales habría que entender aquellos que «transcend the borders of a single culture in their choice of topic» (Pettersson, 2006: 1). En todo caso, estos modelos teóricos se interesan por la literatura como un escenario en el que se desarrollan procesos dinámicos que ponen en entredicho las fronteras identitarias y culturales de una determinada comunidad nacional; por añadidura, suponen una intensa revisión de cuestiones críticas, metodológicas e historiográficas relacionadas con el estudio literario.

Hablar del valor de un texto literario consiste en medir factores lingüísticos, ficcionales, morales, pragmáticos y normativos relacionados con dicho texto, agentes que tienen que ver con el modo en que se ha utilizado el lenguaje, el grado de imaginación alcanzado, el reflejo de experiencias humanas, la ausencia de utilidad práctica inmediata y el nivel de aprecio estético logrado, factores que nada tienen de esenciales y todo de históricos (Eagleton, 2013). Ahora bien, es evidente que - cuando la literatura entra en la siniestra lógica del mercado y el lector se convierte en un sujeto pasivo o, sin más, en un mero consumidor - ese valor de uso se transforma en un valor de cambio. En este sentido, a finales de la pasada década de los ochenta, se comenzó a hablar de una novela light, ligera, despreocupada y superficial que nacía con el claro propósito de agradar al lector, sin incomodarle lo más mínimo, caracterizada por su falta de complejidad formal y estructural, sus contenidos fácilmente digestibles y su carácter de material desechable tras la lectura. Un producto, en definitiva, de usar y tirar. En esto se ha convertido gran parte de la literatura que se publica en la actualidad, sometida a los vaivenes e intereses del mercado. El capitalismo avanzado reduce la literatura a mera mercancía programada para llevar una vida efímera y dotada de un determinado valor de cambio, convirtiéndola en un producto perecedero, envasado con fecha de caducidad. La búsqueda de la posteridad queda sustituida, en la literatura de consumo, por la obsolescencia programada.

Al margen de estas consecuencias económicas y de lo que pueda significar cualquier texto literario, la literatura es siempre un fenómeno de carácter comunicativo, una actividad que surge en un determinado sistema socio-cultural, en cuya definición y construcción participa activamente, y, en este sentido, algunos modelos teóricos desarrollados en estas últimas décadas (pienso en la Semiótica de la Cultura de Iuri M. Lotman, en los Cultural Studies desarrollados por el Grupo de Birmingham, en Pierre Bourdieu y sus conceptos del habitus y del champ littéraire, en el New Historicism, en la Teoría Empírica de la Literatura de Siegfried J. Schmidt, en las teorías de la transferencia cultural, en Itamar Even-Zohar y la Teoría de los Polisistemas, especialmente indicadas estas últimas para aquellos lugares donde conviven distintos sistemas lingüísticos y literarios) han estudiado la literatura sin la rigidez de las viejas disciplinas académicas, vinculadas con frecuencia a los avatares políticos, económicos y culturales del Estado nacional (precisamente, a la crisis de ese modelo político y administrativo que es el Estado nacional le ha seguido otra crisis de los estudios literarios y de las ciencias culturales más acusadamente nacionalistas). Interdisciplinarios para unos, antidisciplinarios 
para otros, muchos de esos modelos teóricos se han interesado por el movimiento experimentado por elementos al traspasar los límites que separan distintos ámbitos culturales; en sintonía con nuestra época, dichos modelos podrían calificarse de posdisciplinarios y han abordado el análisis y la crítica de la literatura fundamentalmente como medio de comunicación e institución social, centrándose sobre todo en las condiciones de producción, circulación, recepción y canonización de los fenómenos literarios, al margen de fronteras lingüísticas y nacionales, con lo cual el concepto de «literatura nacional» — que trabaja en un marco territorial limitado y sobre un modelo explicativo basado en la lengua nacional y la nación — se ve sensiblemente cuestionado. En palabras de Fredric Jameson (1991: 43): «la posliteratura del mundo tardocapitalista no refleja únicamente la ausencia de un gran proyecto colectivo, sino también la cabal inexistencia de la vieja lengua nacional».

En estas circunstancias, nos encontramos con que una buena parte de la literatura actual — presa de la autosatisfacción y el ensimismamiento y reacia a que el texto cumpla una función desalienante y emancipadora - presenta un considerable déficit de pensamiento y, así, muchos escritores huyen de ese bicho raro y peligroso que es la teoría como si se tratara de la peste no sea que les haga pensar y se tambaleen sus planteamientos estéticos. Y habría que señalar que esa «hostilidad contra lo teórico» que Max Horkheimer (1974: 262) veía como un rasgo de época en los años treinta del siglo pasado, y que coincidió con el ascenso del fascismo en buena parte del continente europeo, es un factor que está ganando un preocupante protagonismo en muchos ámbitos del mundo actual, lastrado por la desertización del pensamiento y la trivialización de la cultura.

Así pues, y teniendo en cuenta esta situación de precariedad ideológica y de déficit teórico en que nos encontramos (entrevista ya por Daniel Bell en los años sesenta, cuando publica El fin de las ideologías, e interpretada posteriormente de diversas maneras por autores como Gianni Vattimo, Francis Fukuyama, Jean-François Revel o Gilles Lipovetsky), sería deseable fomentar —si es que queremos entender nuestro tiempo y el lugar que en el mismo ocupa la literatura - «una respuesta teórica modificada» (Jameson, 2004: 85), forzar un desplazamiento del punto de vista desde el que se contempla la producción cultural posmoderna, un movimiento que supone el desmantelamiento de sistemas filosóficos, estéticos y de pensamiento elaborados durante la modernidad y que implica, a la vez, un riesgo de pérdida de sentido. Y la literatura, precisamente por ser un lenguaje donde el sentido se pone permanentemente en juego, puede ser un buen lugar para medir las consecuencias de ese traslado, más aún si pensamos que, como decía Derrida, la literatura no sería nada sin ese riesgo. Sumar en lugar de restar, incluir en vez de excluir. Se trataría de restar territorio a las certezas garantizadas, llevar a cabo una saludable tarea de oxigenación.

Todo esto debería servir para recordarnos que la literatura — como la sociedad en la que surgees siempre resultado de conflictos, tensiones y enfrentamientos de distintos tipos y esas situaciones se dan en todos sus géneros y modalidades, incluidas aquellas que — sometidas a los vaivenes del consumo- pertenecen a la matriz que conocemos con el nombre de cultura de masas, una denominación que, tal como defendió Raymond Williams en Culture and society (1958), más que nombrar una realidad - la propia existencia de una comunidad como masa más o menos homogénea- 
, indica una deriva, una actitud desindividualizadora orientada hacia la estandarización, el control social y el tratamiento de la gente como un sujeto compacto y unitario. Así, además de unos valores estéticos y unos componentes imaginarios, la literatura desarrolla unas determinadas funciones como discurso social: sirve para dotar de cohesión a una comunidad y, al mismo tiempo, para abrir fracturas en los cimientos sobre los que se asienta esa misma comunidad, fomenta unidad y proporciona señas de identidad a un cierto colectivo, sí, pero sobre todo es, puede ser, un lugar idóneo para practicar la crítica de todos los valores y modelos que regulan la vida social de ese mismo colectivo, una crítica por la que algunos escritores han pagado un precio muy alto (ahí están Danilo Kis, acusado por sus colegas más próximos al poder de falsear y traicionar la historia en Una tumba para Boris Davidovich; Salman Rushdie, amenazado de muerte por una fetua del imán Jomeini a raíz de Los versos satánicos; Roberto Saviano, igualmente amenazado por diversas familias camorristas tras la publicación en 2006 de Gomorra). Alimentados por un ciego e indiscriminado odio hacia el arte y la ficción, hemos llegado a una situación en que «la literatura se encuentra sometida a una violencia sin precedentes en su historia» y en que la censura persigue «la ficción en tanto que tal y pretende transformar en delito todo tipo de práctica artística libre» (Salmon, 2001: 11). Kis - para quien el nacionalismo era una ideología banal y totalitaria-, Rushdie, Saviano, supervivientes de un mismo naufragio provocado por la intransigencia y el terror.

En todos estos casos son los textos literarios los que se perciben como transgresores de un determinado sistema — político, religioso, económico - y, así, conductas de este tipo no suponen sino atentados contra lo que, desde un ámbito imaginario y ficcional, apuesta por la emergencia de otros mundos reales y otros modos de relación entre los hombres. De este modo, frente a un mundo cada día culturalmente más estandarizado y uniformado, teledirigido por las grandes empresas de comunicación y las industrias culturales transnacionales, es urgente plantear la oposición de una acción política que reivindique el poder subversivo de la ficción y de otras manifestaciones de creación simbólica, una acción que ponga en contacto, sobre todo, a los que son obligados a callar y a los que no se les permite escribir con quienes no tienen la oportunidad de escuchar o leer (Salmon, 2001).

En el escenario actual sobre las implicaciones de los intercambios y los conflictos culturales, es cada día más frecuente encontrar planteamientos favorables a las particularidades de la diferencia y la interculturalidad. Así, conceptos como multiculturalidad, apertura de paradigmas, pluralismo crítico, elasticidad o flexibilidad teóricas van recubriéndose de una especie de aureola de gloria que otorga prestigio a la vez que, al mismo tiempo, conllevan imprecisiones terminológicas, semánticas e ideológicas. Este proyecto crítico se desarrolla a través de una deliberada confluencia epistemológica y de métodos interpretativos que apuestan por el bricolaje, la apertura, la movilidad y la coparticipación de enfoques, es decir, por sumar y no restar, desde la conciencia de que el conocimiento avanza de forma eficaz únicamente en un territorio caracterizado por la diversidad y que el itinerario que traza el excluyente monopolio del saber es, a medio o largo plazo, el sendero de la cerrazón ideológica. De todas maneras, no es suficiente con prestar atención a la diversidad y complejidad que se esconden detrás de esas diferentes categorías, más próximas al ámbito del simulacro que al de lo real; haría falta, 
en mi opinión, ahondar en los motivos que han conducido a la construcción de un armazón ideológico al servicio del mercado y del capital y, en ese sentido, una literatura crítica y revolucionaria tendría que incluir en su proyecto la visibilización de los mecanismos invisibles que provocan nuestra explotación, llamar la atención sobre el modo en que las distintas violencias subjetivas que se producen en el sistema — reyertas callejeras, delincuencia, mobbing escolar o laboral, etc. — son, en realidad, provocadas por una violencia objetiva o sistémica que define la propia lógica de las relaciones de explotación del capitalismo avanzado (Žižek, 2009).

El ecumenismo, cosmopolitismo e internacionalismo heredados de la modernidad han dejado paso en la posmodernidad a una sociedad mundializada en la que la globalización, con frecuencia, no es tanto un valor del que debamos sentirnos orgullosos como un hecho contra el que habría que rebelarse en la medida que supone, en lo económico, imposición de un modelo injusto y crecientemente insostenible y, en lo cultural, fomento de la uniformidad y anulación de las diferencias. La globalización implica «el espacio del ejercicio del poder dentro del cual las potencias dominantes establecen, en cada período histórico, las reglas del juego que articulan el sistema global» (Ferrer, 2008: 24), es decir, supone la constitución de un sistema de redes en el cual se organizan las relaciones comerciales, las actividades inversoras y financieras de las corporaciones transnacionales y el flujo de personas, capitales e informaciones que sirven a los intereses económicos de esas empresas.

Frente a esa globalización uniformadora que barre las diferencias, una actitud heredera de un cierto cosmopolitismo - representativa a su vez de una particular versión de la posmodernidad — las contempla en un escenario común y les concede un estatuto similar. Se trata, sin embargo, de una actitud blanda y edulcorada, suave y sensiblemente acrítica, partidaria del desarrollo de las diferencias pero al mismo tiempo reacia a promover un marco regulador y normativo, una actitud que ve en el fomento de esas diferencias tan solo riqueza - la expresión más viva del multiculturalismo - y no conflictos y tensiones o relaciones basadas en el ejercicio de la fuerza y el poder. Por el contrario, y aunque no sean las predominantes, en la posmodernidad también encontramos otras maneras sensiblemente diferentes - casi antagónicas — de afrontar esta situación, propuestas orientadas por un cosmopolitismo no solo atento sino también crítico con las diferencias (sobre todo, cuando implican desequilibrios y desigualdades sociales), que va más allá del relativismo y trabaja por la construcción de un escenario que sea capaz de garantizar la pluralidad cultural y la igualdad social, propuestas que, según Baudrillard (2010: 42), han de trabajar sobre la base de un «enfrentamiento que ya no es exactamente político, sino metafísico y simbólico en sentido fuerte».

En cualquier caso, también como discurso cultural, podría decirse que — desde una perspectiva nacionalista - la literatura supone un factor de cohesión determinante en los procesos de construcción social, esto es, se trata de un rasgo distintivo de la identidad nacional que puede emplearse para alcanzar objetivos nacionalistas. Pero la situación de la literatura en el circuito de los discursos sociales es - más allá de ese alcance nacionalista y desde un punto de vista institucional- enormemente inestable, y ello en una época como la nuestra en la que casi todo se muestra inseguro y surgen procesos de identidad bajo diferentes banderas: nación, género, raza, religión, lengua, ideas políticas, 
orientación sexual, etc., procesos basados más en lo que separa a cada grupo del resto que en lo que une a los miembros de un mismo grupo identitario (Hobsbawm, 2000; Saldaña, 2013).

La literatura puede ser un buen lugar de encuentro de esas diferentes banderas; contra toda forma de exclusión y dominación, lo literario puede convertirse en un exponente idóneo de una política cultural y de relaciones internacionales basada en la diversidad, la tolerancia y la colaboración y, en este sentido, algunos trabajos de Edward W. Said (1996) nos han enseñado a (re)leer los (con)textos canónicos occidentales como síntomas del poder colonial de la metrópoli, a la luz de las huellas que el imperialismo ha dejado sobre la arena de la historia. Y ahí desempeñan un papel importante conceptos tan relacionados entre sí como puedan ser los de «contraescritura», «contradiscurso», «reinscripción» y «lectura en contrapunto», glosados por Said y otros habituales de los estudios poscoloniales, en los que se ha querido ver ataques contra las formas canónicas discursivas y de recepción, desarrollos de una subversión cultural, representaciones ideológicas de una transformación política, en definitiva, configuraciones simbólicas de un discurso anticolonial.

La contraescritura desarrolla una estrategia subversiva, un acto crítico tendente a desmontar las bases artísticas y epistemológicas sobre las que se asienta el texto que sirve como referente, una acción política que intenta desvelar los fundamentos culturales y los presupuestos ideológicos de las obras pertenecientes al canon literario metropolitano, señalar sus contradicciones y los intereses a que responden y, de paso, sugerir otras posibilidades de lectura, tal como se ha hecho desde la crítica feminista (Kate Millett, Elaine Showalter, Shere Hite, Judith Butler, etc.) y desde la crítica poscolonial (Frantz Fanon, Edward W. Said, Gayatri Chakravorty Spivak, Homi K. Bhabha, etc.) al optar por un desplazamiento de la representación, liberando a la mujer y al hombre negro de la obligatoriedad de tener que identificarse, en contra de sí mismos, con personajes que no les representaban.

Está en juego el tipo de mundo del que deseamos formar parte y, en ese sentido, es necesario cambiar algunos planteamientos en nuestros sistemas de valores, cambios que incluirían un esfuerzo epistemológico que reconsiderara nuestros domesticados hábitos de conocimiento: «en una teoría crítica posmoderna toda forma de conocimiento crítico debe comenzar por ser una crítica al conocimiento mismo» (De Sousa Santos, 2005: 105), un esfuerzo que muy probablemente tendría unas consecuencias políticas inmediatas puesto que dicho proceso supondría la sustitución de un conocimiento de tipo regulativo por un conocimiento de tipo emancipador (De Sousa Santos, 2005). El primero, tendente tan solo a domesticar el caos y convertirlo en orden, se opone al conocimiento emancipador, orientado hacia la crítica y superación del modelo colonial, contrario a los conceptos de autoridad y jerarquía y a favor de la solidaridad intercultural. Contenido ético y radical autoconciencia, valores de una escritura literaria que emerge como actividad testimonial frente a un sistema social alienante y devastador, una actividad impulsada por ese objetivo que Danilo Kis consideraba irrenunciable: salvar aquello que vive amenazado por la desaparición. Así, incertidumbre, inseguridad, inestabilidad, escepticismo y ambigüedad son rasgos inherentes de una literatura que escapa del dogmatismo y el gregarismo, ingredientes dominantes de esa balsa de aceite que trata de ahogar cualquier elemento crítico en la práctica literaria. 
Uno de esos elementos amenazados por la desaparición lo encontramos en el viejo concepto de la teoría marxista de la lucha de clases, reflejo de las fracturas, grietas, tensiones y conflictos inherentes a la mayor parte de las sociedades, donde la abundancia y riqueza en las que vive una parte de la población y la aparente multiculturalidad que se respira se presentan como rasgos de alcance general al tiempo que tratan de vaciar de contenido y dejar sin argumentos dicha lucha. Así, en los estudios culturales se prefiere hablar de multiculturalismo, de culturas distintas y no de diferentes clases que coexisten en una misma sociedad, aunque sea un hecho comprobado que esas culturas nunca conviven en régimen de igualdad (dime cómo nombras el mundo y te diré el mundo en el que vives). En $L a$ lucha de clases en Francia de 1848 a 1850, Marx describió la situación social en ese país en vísperas de la revolución de 1848 y se refirió a una aristocracia financiera que dictaba leyes, controlaba la administración del Estado y la opinión pública a través de la prensa, una aristocracia financiera que ostentaba todos los poderes constituidos y que aspiraba únicamente a enriquecerse no mediante la producción sino a través del robo de la riqueza ajena (una situación que, aunque alejada en el tiempo, nos puede resultar muy familiar dadas las semejanzas que encontramos con algunas situaciones contemporáneas, dominadas por los intereses de una economía financiarizada).

Así, la experiencia literaria podría consistir en la aceptación de una contingencia, la posibilidad de que se abra una grieta por la que se pueda intuir algún horizonte utópico, el desdoblamiento de una realidad inicial en una realidad imaginaria que no se deja atrapar, cuyo rostro desaparece al ser contemplado y cuya palabra es solo el anuncio de una oportunidad: la experiencia de la literatura contemporánea es en gran parte una experiencia del margen y el destierro permanente, del vaciado de sí misma y el alejamiento del centro; probablemente no haya ninguna otra actividad tan consciente de la pérdida como la literatura, una práctica que en la creación de sus propias imágenes conlleva el estigma de su misma destrucción, la señal inequívoca de su inminente desaparición, una práctica en la que una voz se deja oír para pronunciar y fijar una palabra errante en el hueco más profundo de la ausencia. Tales pudieran ser acciones derivadas de un pensamiento literario no sometido que viese en determinadas conductas artísticas no tanto modelos de referencia como oportunidades para ejercer la crítica y la resistencia frente a cualquier sistema basado en la neutralización de las diferencias. Porque la literatura continúa siendo, en estos tiempos de penurias sociales y de reacción ideológica, un buen bastión frente a la estandarización, simplificación y homogeneización dominantes, un lugar idóneo para comprender que la existencia es en gran medida complejidad y dinamismo y que el saber - como defendía el Sócrates platónico de la República - se muestra siempre inseguro de sí mismo, es una práctica en permanente construcción, imperfecta, inacabada, que responde a la fórmula no tanto de un hecho como de un haciéndose.

En estas circunstancias, la literatura — a partir de esas categorías que le son consustanciales: el multiperspectivismo, la polifonía, la polisemia, la multiplicidad de significados - no ha cesado de dibujar escenarios complejos y cambiantes, atentos en todo caso a los conflictos y contradicciones que caracterizan la vida cultural y espiritual del ser humano. Me refiero, claro, a cierto tipo de literatura, determinados textos y autores que han hecho del lenguaje literario no tanto una herramienta de 
representación como de reflexión, crítica y transformación del mundo. Y es que la literatura también ha sido cuestionada desde muy diversos frentes: «fue acusada de elitista, de haber quedado fuera de lugar en un mundo eminentemente audiovisual, de haberse agotado a sí misma después de la insistente autorreflexión, de haber sido absorbida casi sin excepciones por el mercado» (Montaldo, 2010: 176), esto es, nos encontramos con una práctica literaria incapaz unas veces de seguir el ritmo de los avances tecnológicos, desvinculada del mundo y obsesionada por volver una y otra vez sobre sus propios asuntos, convertida otras en una mercancía comercial plegada ya a los intereses económicos de la industria cultural.

Iuri M. Lotman (1996) ya percibió el carácter global de la semiosfera del mundo contemporáneo, un espacio semiótico en el que la interconexión de sus elementos no es una metáfora ni una aspiración sino una realidad que nos reclama una actitud más crítica y una conciencia más informada ante los movimientos migratorios internacionales y los nuevos escenarios de mestizaje e hibridación culturales que generan, escenarios fronterizos donde el pensamiento no responde a pautas prefijadas sino que emerge como un lugar en construcción, un paradigma que ha de afrontar las nuevas situaciones generadas. Movimiento y transformación frente a parálisis y estatismo, la frontera es una oportunidad para el contacto y el reconocimiento de territorios diferentes, la metáfora espacial más significativa de una posmodernidad que ha hecho del dinamismo y la inestabilidad algunas de sus señas identitarias y, en esas circunstancias, cierta literatura - al hilo de una actitud radicalmente crítica que entiende la cultura no como fiesta y celebración sino como lugar de confrontación y exposición de tensiones sociales y políticas - hunde sus raíces sobre un escenario fronterizo en permanente construcción, sobre una encrucijada en la que confluyen senderos procedentes de distintos orígenes y de la que parten caminos hacia diferentes destinos; ahora bien, y dado que esa actitud crítica no interesa lo más mínimo a la mayor parte de la industria cultural y editorial y de los medios de comunicación, que funcionan muchas veces como voceros de unos mismos intereses, habrá que aceptar el desafío que dicha conducta nos plantea: leer la palabra desterrada y errante, oír la palabra del otro, del extranjero, un desafío que conlleva, claro, el riesgo de perder nuestra propia identidad (Saldaña, 2018).

Dado que hay, como hemos tenido oportunidad de recordar a lo largo de estas páginas, una posmodernidad que fomenta un pensamiento de la diferencia, lo múltiple y lo plural, atenta a esos otros escenarios que los paradigmas dominantes no suelen frecuentar, esa asociación tan extendida de posmodernidad y relativismo resulta en muchas ocasiones, además de una simplificación, una falacia. Así pues, el análisis inicial propuesto de la posmodernidad desde algunos sectores de la izquierda política como un fenómeno afirmativo, esto es, acrítico, vinculado a formas sociales y culturales neoconservadoras es extremadamente débil y reduccionista. La perspectiva con que contemplamos el fenómeno es suficiente para apreciar la posmodernidad como una realidad histórica y cultural con perfiles definidos, una realidad en la que se elaboran prácticas artísticas con elevados contenidos críticos y de oposición que revelan profundas contradicciones y tensiones internas del sistema. Que la idea dominante que ha arraigado en Occidente sea inseparable de la práctica de un liberalismo político y económico radicalmente injusto con los más desfavorecidos no quiere decir que no haya otras ideas 
capaces de interpretar el mundo — no solo el occidental- de otras maneras ni que, en otras condiciones, no pueda surgir una nueva «idea occidental» dominante distinta de la actual. Nuevas situaciones que generan nuevos conflictos que demandan a su vez nuevas respuestas. En todo caso, cabe pensar que el deseo de ver y la voluntad de construir de otra manera son inherentes a una cierta sensibilidad posmoderna y luchar para que la democracia liberal al servicio de los intereses del capitalismo no se convierta — como temiera Lyotard - en el horizonte irrebasable del tiempo. En este sentido, conceptos como los de disensión, diferencia, descentramiento y deconstrucción se han hecho habituales en el arte y el pensamiento de nuestro tiempo, y el último Lyotard — que sigue aquí la estela marcada por Adorno - aboga por la refundación de una razón capaz de oponerse al totalitarismo presente, es decir, por la reactivación de un «racionalismo crítico» (Lyotard, 1995: 86).

De hecho, y a pesar de la diversidad y complejidad de discursos teóricos y formas artísticas que pueblan nuestro presente, es urgente realizar un esfuerzo para superar la fascinación inicial que puede experimentarse ante esa riqueza de prácticas culturales y elaborar, a partir de esa diversidad, una teoría posmoderna de la identidad colectiva que refleje los latidos de pluralidad y resistencia cultural que se dejan oír - algunos de ellos con dificultad - en cualquier sociedad. En mi opinión, si el conocimiento desea seguir avanzando, no podrá dejar de mantener una actitud crítica consigo mismo a la vez que tendrá que hacer un esfuerzo por atender los movimientos internacionales de población, las relaciones transculturales, los fenómenos migratorios y las hibridaciones; los modelos de análisis e interpretación deberán ser más complejos y no podrán excluir formas artísticas emergentes, cada día más visibles, como por ejemplo las surgidas en las culturas de los suburbios o de las minorías. Vivimos hoy una situación extraña: los estudios culturales se han convertido en un cuerpo de producción teórica que ha alcanzado un notable desarrollo, caracterizado por una rica diversidad de enfoques e intereses pero también sometido a un cierto grado de exclusión y marginalidad promovido desde la academia.

\section{Referencias bibliográficas}

AA. VV. (2006). Literary History: Towards a Global Perspective, 4 vols., Berlín, Walter de Gruyter. ANDERSON, Perry (2000). Los orígenes de la posmodernidad, trad. de L. A. Bredlow, Barcelona, Anagrama.

APARICIO MAYDEU, Javier (2015). La imaginación en la jaula. Razones y estrategias de la creación coartada, Madrid, Cátedra.

BAUdRILlard, Jean (2010). La agonía del poder, 2. ${ }^{\text {a }}$ ed., trad. de M. Pérez Colina y A. C. Conde, Madrid, Círculo de Bellas Artes.

BordeloIs, Ivonne (2005). La palabra amenazada, Buenos Aires, Libros del Zorzal.

De Sousa SANTOS, Boaventura (2005). El milenio huérfano. Ensayos para una nueva cultura política, presentación de J. C. Monedero, Madrid, Trotta.

Eagleton, T. (2005). Después de la teoría, trad. de R. García Pérez, Barcelona, Debate.

- (2013). El acontecimiento de la literatura, trad. de R. García Pérez, Barcelona, Península. 
102 Tropelías. Revista de Teoría de la Literatura y Literatura Comparada, número extraordinario 6 (2020) Alfredo Saldaña Sagredo

ETTE, Ottmar (2009). «Hacia una poética del movimiento: literaturas sin residencia fija», Afinidades, 02, 85-96.

FERRER, Aldo (2008). «Globalización, desarrollo y densidad nacional», Le Monde diplomatique, ed. española, 151, mayo, 24.

Frow, John (1991). «Postmodernism and Literary History», en D. Perkins, ed. (1991), 131-142.

HobsBAwM, Eric J. (2000). «Los nuevos nacionalismos», Pasajes, enero-abril, 2, 29-34.

HorkHeimer, Max (1974). Teoría crítica, trad. de E. Albizu y C. Luis, Buenos Aires, Amorrortu editores.

Hutcheon, Linda, y Mario J. VALDÉs, eds. (2002). Rethinking Literary History: A Dialogue on Theory, Oxford y Nueva York, Oxford University Press.

JAMESON, Fredric (1991). El posmodernismo o la lógica cultural del capitalismo avanzado, trad. de J.

L. Pardo Torío, Barcelona, Paidós.

(2004). Una modernidad singular. Ensayo sobre la ontología del presente, trad. de H. Pons, Barcelona, Gedisa.

LJunG, Per Erik (2006). «Inventing Traditions: A Comparative Perspective on the Writing of Literary History», en AA. VV. (2006), vol. 3, Literary Interactions in the Modern World 1, 30-66.

Lotman, Iuri M. (1996). La semiosfera I. Semiótica de la cultura y del texto, ed. y trad. de D. Navarro, Madrid, Cátedra / Universitat de València.

LyOTARD, Jean-François (1995). La Posmodernidad (explicada a los niños), 5. a ed., trad. de E. Lynch, Barcelona, Gedisa.

MARX, Karl (1945). Historia crítica de la teoría de la plusvalía, trad. y pról. de W. Roces, México D. F., Fondo de Cultura Económica.

Meschonnic, Henri (2017). Para salir de lo postmoderno, trad. de H. Savino, Buenos Aires, Cactus / Tinta Limón Ediciones.

Montaldo, Graciela (2010). Zonas ciegas. Populismos y experimentos culturales en Argentina, Buenos Aires, Fondo de Cultura Económica.

PERKINS, David, ed. (1991). Theoretical Issues in Literary History, Cambridge (Massachusetts), Harvard University Press.

PetTERSSON, Anders (2006). «Introduction: Concepts of Literature and Transcultural Literary History», en AA. VV. (2006), vol. 1, Notions of Literature across Times and Cultures, 1-35.

SAID, Edward W. (1996). Cultura e imperialismo, trad. de N. Catelli, Barcelona, Anagrama.

SALDAÑA, Alfredo (1997). Modernidad y posmodernidad: filosofía de la cultura y teoría estética, Valencia, Episteme.

- (2004). «Posmodernidad, historia, literatura», en L. Romero Tobar, ed., Historia literaria / Historia de la literatura, Zaragoza, Prensas Universitarias de Zaragoza, 87-98.

- (2013). La huella en el margen. Literatura y pensamiento crítico, Zaragoza, Mira Editores. 
(2017). «¿Cabe algún tipo de literatura política entre las literaturas de consumo?», en L. Alburquerque-García, J.-L. García Barrientos y R. Álvarez Escudero, eds., Escritura y teoría en la actualidad, Actas del II Congreso Internacional de ASETEL, Madrid, CSIC, 2017, 81-89.

(2018). La práctica de la teoría. Elementos para una crítica de la cultura contemporánea, Santiago de Chile / Barcelona, RiL editores.

SALMON, Christian (2001). Tumba de la ficción, trad. de T. Kauf, Barcelona, Anagrama.

SANZ, Marta (2014). No tan incendiario, Cáceres, Editorial Periférica.

SANZ VillanUEVA, Santos (1996). «El archipiélago de la ficción», Ínsula, 589-590, 3-4.

ŽIŽEK, Slavoj (2009). Sobre la violencia. Seis reflexiones marginales, trad. de J. A. Fernández, Buenos Aires, Paidós. 